Check for updates

Cite this: RSC Adv., 2017, 7, 21467

Received 25th February 2017

Accepted 3rd April 2017

DOI: 10.1039/c7ra02347b

rsc.li/rsc-advances

\section{Distinctive oil shale pyrolysis behavior in indirectly heated fixed bed with internals}

\begin{abstract}
Lanxin Lin, ${ }^{\text {ab }}$ Dengguo Lai, ${ }^{\text {ab }}$ Zhen Shi, ${ }^{\text {ab }}$ Zhennan Han $^{\text {ab }}$ and Guangwen Xu (D)*ac
Intrinsic characteristics of oil shale pyrolysis in a fixed bed reactor with internals have been investigated in this study. Mounting particularly designed internals in fixed bed reactor improved shale oil production to up to $90 \%$ yield by Fischer assay. Comparing particle characteristics at different radial positions of the reactors with and without internals demonstrated that, inside the particle bed with internals, the product flow was regulated to move from the high-temperature zone (outer) to low-temperature zone (center), which reduced the secondary reactions of released volatiles. Terminating oil shale pyrolysis at central particle bed temperatures of $150,300,450$, and $550{ }^{\circ} \mathrm{C}$ showed that the contents of vacuum gas oil and heavy oil in the shale oil produced had increased from $9.63 \mathrm{wt} \%$ to $53.29 \mathrm{wt} \%$. The volatile contents of particles in the inner layer of the reactor slightly increased in the early stage of pyrolysis and, in turn, decomposed to form pyrolysis products as the temperature was raised. The adsorption or condensation of liquids on the surface of particles gradually increased from the outer region to the central region of the reactor due to the regulated product flow direction and low temperatures in the central zone of the reactor causing heavy components to condense. Increasing the degree of pyrolysis was also found to decrease the alkene, aromatic, and cycloalkane contents in shale oil, but increased those of alkane and heteroatomic compounds. These results demonstrate that adopting internals into oil shale pyrolysis optimized the product flow direction and selectively directed secondary reactions to occur for heavy volatile species only.
\end{abstract}

\section{Introduction}

Alternative and renewable energy sources have received increasing attention in recent years as fossil fuel consumption has grown. Oil shale is among the most promising alternative energy sources because of its enormous reserves and plentiful aliphatic organic compounds. ${ }^{1}$ Available oil shale utilization patterns have been established in several countries since the 1960s. Combusting oil shale to generate power could supply domestic industrial users, with retorted shale oil considered a potential resource to offset the future crude oil scarcity. The utilization of retorted shale oil requires a comprehensive utilization mode, as reported by many studies. ${ }^{2-6}$

Several representative oil shale retorting processes have been developed and are still in service, such as in situ underground retorting and Tosco-II technology in the USA, the Kiviter process in Estonia, the Petrosix process in Brazil, the Galoter process in Russia, Enefit-280 technology in Germany and Estonia, the Alberta Taciuk process (ATP) in Australia and Canada, the

${ }^{a}$ State Key Laboratory of Multi-Phase Complex Systems, Institute of Process Engineering, Chinese Academy of Sciences, Beijing 100190, China. E-mail: gwxu@ ipe.ac.cn; Fax: +8610 82629912; Tel: +861082544886

${ }^{b}$ University of Chinese Academy of Sciences, Beijing 100049, China

'Institute of Industrial Chemistry and Energy Technology, Shenyang University of Chemical Technology, Shenyang 110142, China
Lurgi-Ruhrgas process in Germany, and the Fushun process in China. ${ }^{4-9}$ Of these, Tosco-II, Galoter, Enefit-280, ATP, and LurgiRuhrgas processes adopt a solid heat carrier method to heat oil shale particles and achieve relatively high oil yields. However, the resultant liquid products usually exhibit high dust intake due to inherent technical defects. Many studies on oil-dust characteristics and separation have been conducted, but a comprehensive solution for the dust-intake problem in pyrolysis had yet to be developed..$^{10}$ Gas heat carrier retorting technology is employed in the Petrosix, Kiviter, and Fushun retorting processes. However, these methods only process largeparticle feedstock. Excessive air pumped into a Funshun furnace causes oil combustion in the pyrolysis stage, lowering the shale oil yield to $65 \%$ by Fischer assay. Process analysis is applied to optimize operating parameters and improve oil production efficiency. ${ }^{11}$ An in situ retorting process has been proposed for deeply buried oil shale, but this technology requires long-term verification for application. ${ }^{4}$ Therefore, no existing retorting processes provide satisfactory pyrolysis performance for oil shale, especially for particle sizes below 10 $\mathrm{mm}$. In particular, innovative retorting technologies are required for small oil shale particles to achieve high oil yield and quality simultaneously.

Particularly designed internals, comprising a central gas collection pipe and a number of metallic plates, have been 
employed to improve oil shale pyrolysis production in indirectly heated fixed bed reactors. ${ }^{12-14}$ An innovative reactor with internals was evaluated by comparing the heating rate of oil shale particles and pyrolysis product distribution. With the heating rate to particles improved, especially in the central region, the resultant shale oil yield was afforded in $90 \%$ oil yield by Fischer assay. Raising the reactor temperature from $600{ }^{\circ} \mathrm{C}$ to $1000{ }^{\circ} \mathrm{C}$ benefited shale oil production, which was in contrast to almost all other reports in the area, which show higher pyrolysis temperatures lead to lower oil yield. In conventional indirectly heated fixed bed reactors, it is generally difficult to achieve high oil yields at high reaction temperatures due to unavoidable significant secondary reactions of volatiles. ${ }^{15-18}$ In contrast, devised internals can reduce cracking in the reactor to achieve a higher shale oil yield at higher heating or reaction temperatures. Matching the product flow field with temperature distribution in the reactor using internals has been speculated to avoid excessive cracking of primary products and improved pyrolysis production. Therefore, further understanding of the detailed pyrolysis characteristics of the new reactor and its superiority are required to guide industrial applications of the technology.

Many studies have focused on the behavior and kinetics of oil shale pyrolysis, which are needed for reasonable analysis and optimization guidance. ${ }^{15-22} \mathrm{Al}$-Ayed et al. adopted secondorder kinetics to model liquid accumulation ${ }^{15}$ and first-order kinetics to fit the total weight loss of oil shale in a fixed bed. ${ }^{16}$ In contrast, various parameters, such as heating rate, final temperature, particle size, density, and additional minerals, have been investigated to clarify their effects on oil shale pyrolysis at various scales. ${ }^{22-32} \mathrm{~A}$ heating rate of $10{ }^{\circ} \mathrm{C} \mathrm{min}^{-1}$ for oil shale particles is optimal for obtaining a high oil yield..$^{26-29}$ The internals adopted in the preceding reactor gave an obvious improvement on heating rate. ${ }^{12-14}$ Nonetheless, this improvement was not as effective at altering pyrolysis behavior in indirectly heated reactors. ${ }^{12,13}$ Lan et al. obtained a maximal shale oil yield at a reaction-stopping temperature of $550{ }^{\circ} \mathrm{C} .^{30}$ Lai et al. demonstrated that the oil yield decreased with increasing temperature by conducting an oil shale pyrolysis series with and without ash. ${ }^{31}$ Zhang et al. investigated the impact of residence time on the pyrolysis product in a fluidized bed. ${ }^{33}$ These studies were all performed in reactors without the aforementioned internals. ${ }^{34}$ Pyrolysis behavior in fixed bed reactors with internals and the working mechanism of internals have yet to be reported. Therefore, a targeted fundamental investigation of oil shale pyrolysis in this innovative fixed bed reactor with internals was conducted in this study.

\section{Experimental section}

\subsection{Materials and apparatus}

Oil shale was obtained from Huadian oil shale mine, and was sieved to a particle size of $0-5 \mathrm{~mm}$ for use in experiments. The properties of Huadian oil shale are shown in Table 1. The drybase oil content was $12.78 \mathrm{wt} \%$ by Fischer Assay. Silica sand (1-2 $\mathrm{mm}$ ) was used in the study to replace a portion of the oil shale particles, which had been pretreated at $900{ }^{\circ} \mathrm{C}$ for $3 \mathrm{~h}$.

A conventional fixed bed reactor without internals was used as reference in this work. The pyrolysis investigation was conducted in a reactor mounted with a central collection pipe and four metallic plates. The plates were welded perpendicular to the fixed bed reactor wall. Fig. 1 shows schematic diagrams of the two reactors used. The reactors had an inner diameter of 200 $\mathrm{mm}$, and effective volumes for loading oil shale of around 5600 mL. From the wall to the center of the reactor (Fig. 1), both reactors were demarcated into three layers $(a-c)$ in a radial direction. Three temperature measurement points were present in layers a-c to record real-time heating curves inside these layers. The experimental system was the same as used in our previous work ${ }^{14}$ consisting of four parts: pyrolysis, liquid collection, pressure control, and gas sampling.

\subsection{Pyrolysis and analysis}

The furnace was heated to $850{ }^{\circ} \mathrm{C}$ and held until the pyrolysis test was completed. For each individual experiment, dried Huadian oil shale $(4900 \mathrm{~g})$ was loaded into the test reactor. In some tests, the oil shale particles in the outboard layer were replaced with silica sand of equal volume. After connecting to the experimental system, the reactors were placed into the heated furnace and quickly covered with silica wool. The pressure in the reactor was maintained at $1 \mathrm{~atm}$ using a vacuum pump. Pyrolysis products were exhausted from the top of the reactor and cooled in a downstream condenser pipe. The cooled liquid product was collected in a bottle. Residual low-boiling components in the gaseous product were adsorbed using three acetone bottles. The pyrolysis gas was then passed through a wet gas meter to measure the volume and then successive through a few clean bottles to remove dust, moisture, and hydrogen sulfide. Every $5 \mathrm{~min}$, a gas sample was taken for compositional analysis by GC. When the central temperature measurement point reached $150{ }^{\circ} \mathrm{C}, 300^{\circ} \mathrm{C}, 450{ }^{\circ} \mathrm{C}$, and $550{ }^{\circ} \mathrm{C}$, the reactor was removed from the furnace to terminate pyrolysis and the reactor was cooled in air.

Subsequent product treatment was conducted for all pyrolysis experiments conducted at central temperatures of $150{ }^{\circ} \mathrm{C}$,

Table 1 Properties of Huadian oil shale tested

\begin{tabular}{|c|c|c|c|c|c|c|c|c|c|}
\hline A & $\mathrm{V}$ & FC & $\mathrm{C}$ & $\mathrm{H}$ & $\mathrm{N}$ & $\mathrm{O}^{a}$ & S & Fischer Assay wt\% & HHV kcal kg ${ }^{-1}$ \\
\hline
\end{tabular}

${ }^{a} \mathrm{O}$ content was obtained from the difference of balance. 


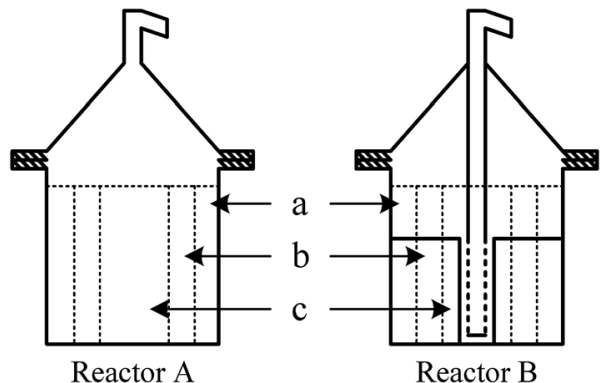

Fig. 1 Schematic illustrations of particle layers $a-c$ in reactors $A$ and $B$.

$300{ }^{\circ} \mathrm{C}, 450{ }^{\circ} \mathrm{C}$ and $550{ }^{\circ} \mathrm{C}$. All yields were given relative to the dry mass of treated oil shale.

After cooling to room temperature, oil shale char from the three layers (a-c in Fig. 1) was sampled for further analysis. Accordingly, the char samples were denoted a-c. The char yield was calculated from the product weight relative to the mass of loaded oil shale. Condensate (or adsorbate) on $1.0 \mathrm{~mL}$ char, sieved to $0.2-1.0 \mathrm{~mm}$, was dissolved (with the char) in $50 \mathrm{~mL}$ petroleum ether (boiling range: $90-110{ }^{\circ} \mathrm{C}, \mathrm{AR}$ ). The obtained solution was scanned using an ultraviolet spectrophotometer (TU-1901) at $1 \mathrm{~nm} \mathrm{~s}^{-1}$. Char samples were smashed to a powder below $0.1 \mathrm{~mm}$ in size for proximate analysis.

Liquid from the scrubbing bottles was mixed with the acetone solutions from the washing pipelines and vessels, and rotary evaporation was performed to remove acetone. The resultant residual liquid was blended with shale oil in the liquid collection bottle of the condenser. Intake water in the blended liquid was first separated by oil-water delamination, and the remaining moisture in the oil phase was measured by a standard method using toluene as an azeotrope. This allowed the water and oil yields to be estimated. The dehydrated shale oils collected from different central temperatures at termination $\left(150,300,450\right.$, and $\left.550{ }^{\circ} \mathrm{C}\right)$ were analyzed to obtain the distributions of distillation fractions according to boiling points. A GC 7890A instrument (Agilent) was employed to perform simulated distillation fraction analysis. The chemical compositions of the four oil samples were determined using a GC-MS QP 2010 Ultra instrument (Shimadzu). All analytical methods used for shale oil in this study have been detailed in our previous work. ${ }^{\mathbf{1 3 , 1 4}}$ The pyrolysis gas yield was calculated from the measured gas volume (in a gas meter) and the gas composition was obtained using a micro GC (Agilent 3000A).

\section{Results and discussion}

\subsection{Temperature distribution}

Particularly designed internals have been successfully applied to improve the oil yield and heating efficiency in an indirectly heated fixed bed reactor in our previous work. ${ }^{12-14}$ Taking the heating curve at or near the reactor center to characterize the heating efficiency of the particle (oil shale) bed in the reactor showed that the heating rate of the particles at the measured positions was nearly doubled when using internals. Three temperature measurement points in layers a-c were recorded to capture the real-time temperature distribution in the tested reactors with or without internals.

Fig. 2 compares the heating curves for oil shale in the layers a-c. The heating furnace temperature for the tests was $800{ }^{\circ} \mathrm{C}$. Overall, reactor $\mathrm{B}$, which had internals, gave a much shorter heating time than reactor $A$ to reach a temperature of $550{ }^{\circ} \mathrm{C}$ at the measured bed center. This implied faster heating in the reactor with internals, in agreement with our previous studies. ${ }^{12-14}$ Fig. 2 also shows that the difference between the heating curves of the two reactors was largest in layer $\mathrm{c}$ and smallest in layer a. This meant that the internals mainly facilitated heating to particles in the inner (core) bed.

Layer a, nearest the reactor wall, was quickly heated to $700{ }^{\circ} \mathrm{C}$ in $20 \mathrm{~min}$, and subsequently exceeded $800{ }^{\circ} \mathrm{C}$. This formed a high-temperature zone in layer a in the early stage of the experiment, resulting in fast oil shale pyrolysis. At this stage the temperatures in layers $\mathrm{b}$ and $\mathrm{c}$ were below $200{ }^{\circ} \mathrm{C}$, which were too low to give oil shale pyrolysis. There was little difference between the two reactors in the initial (first $10 \mathrm{~min}$ ) temperature rise characteristics from outboard layer a to central layer $c$.

As the experiment continued, the heating rates of layers $b$ and $\mathrm{c}$ in reactor $\mathrm{B}$ (with internals) gradually became higher than those in reactor $\mathrm{A}$. The average heating rate of oil shale in layer $\mathrm{c}$ was $4{ }^{\circ} \mathrm{C} \min ^{-1}$ in reactor $\mathrm{A}$, but was elevated to about $10{ }^{\circ} \mathrm{C} \mathrm{min}^{-1}$ in reactor $\mathrm{B}^{26-29}$ The devised internals enhanced heating by aligning the field of temperature, from high to low, with the flow direction. ${ }^{12-14}$ The central gas collection pipe guided the hightemperature gaseous products to flow from the outboard to the central zone, with heat taken from the gas contributing to heating of the core bed. ${ }^{12,13}$ Meanwhile, the metallic plates added extra heating surfaces to promote heat transfer from the reactor wall to the particle bed. ${ }^{14}$ At the end of the test, layer $\mathrm{b}$ in reactor $\mathrm{A}$ has been heated to a higher temperature than that in reactor $\mathrm{B}$, indicating that a higher temperature area had been created inside reactor A. Therefore, the employed internals greatly improved heating efficiency from the bed wall to the center and altered the temperature gradient in the bed.

\subsection{In-bed product flow direction}

A decreasing temperature gradient is present from the outboard to the center of an indirectly heated fixed bed reactor. This

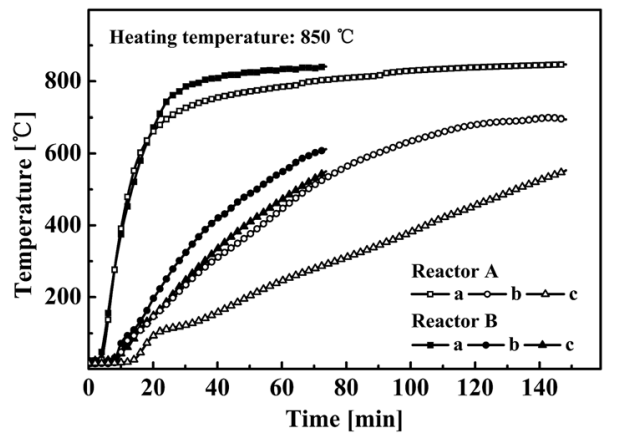

Fig. 2 Heating curves for layers $a-c$ in reactors with and without internals. 
gradient has a critical impact on the in-bed secondary reactions of pyrolysis products. If the products flowed through the hightemperature outboard, excessive product cracking would occur. In contrast, secondary reactions are likely to be weak in the reactor center. Herein, the product flow direction in the reactors with and without internals was clarified to obtain better understanding of the system.

A char bed gives a smaller pressure drop than an oil shale bed of the same thickness. ${ }^{13}$ As pyrolysis progresses in an indirectly heated fixed bed, a char layer is formed on the outboard or annulus, causing the gaseous pyrolysis products to flow toward the reactor wall. The pyrolysis products must undergo a large amount of secondary reactions in the outboard zone to greatly decrease shale oil production. The internals potentially reduce this problem by redirecting the flow of pyrolysis products into the pyrolysis reactor. ${ }^{12-14}$ Silica sand (1.0-2.0 $\mathrm{mm})$ has better gas permeability than oil shale. Therefore, silica sand was used to imitate char by replacing oil shale particles with silica sand in the outer layer of the reactor. This also ensured that no chemical change would occur in the sand layer, while volatile products were only generated by pyrolyzing oil shale in the central zone. Observing the color change of the silica sand allowed the flow direction of volatiles formed in the bed center to be determined.

Fig. 3 shows top-down photos inside the beds after pyrolysis tests in reactors (A) without and (B) with internals. The outer layer filled with silica sand had obviously different colors. Sand particles were blackened in reactor A, also having a deeper color at inner positions close to the central oil shale layer. This was caused by the deposition of unreacted matters, including carbon, formed from pyrolysis. Therefore, without mounting

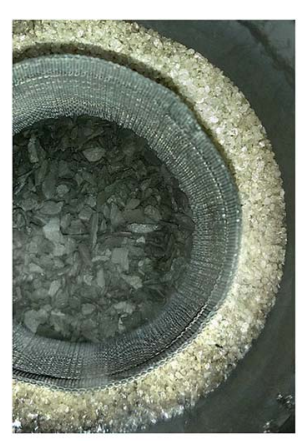

Reactor A

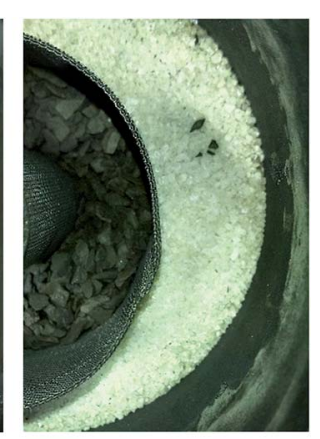

Reactor B
Fig. 3 Evidence of secondary cracking through color change on particles in the vicinity of the reactor wall for reactors $A$ and $B$. internals in reactor $\mathrm{A}$, the pyrolysis products flowed outwards toward the reactor wall. In contrast, Fig. 3 shows that the loaded silica sand remained white in reactor $\mathrm{B}$ with internals, demonstrating that the generated pyrolysis products did not flow into the outer region next to the reactor wall. This verified that the use of particularly designed internals in a fixed bed pyrolyzer resulted in the internal flow of pyrolysis products from the wall zone to the central zone around the gas collection pipe.

Samples of oil shale or char were taken from layers a-c at different reaction stages or reaction times and analyzed to further understand the product flow direction in reactor B with internals. Table 2 summarizes the results of proximate analysis for all samples, in which the reaction stage is shown by different temperatures reached at the monitored central position (representing the bed center). At all pyrolysis stages, from the outer layer a to central layer c, the ash and fixed carbon contents of the analyzed samples decreased, but their volatile contents conversely increased. This agreed with the temperature gradient in the reactor that high-temperature in the outer layer caused a high degree of pyrolysis. Meanwhile, as the reaction progressed (measured temperature increased) the volatile contents of all samples tended to decrease gradually, but those of layers $\mathrm{b}$ and $\mathrm{c}$ initially increased slightly or did not vary until the measured central temperature was over $300{ }^{\circ} \mathrm{C}$. As the flow of products was from the outer wall to center, species with high boiling points (or heavy species) would be condensed and adsorbed on the surface of inner-layer particles when their temperatures were low, such as below $300{ }^{\circ} \mathrm{C}$. This explained the slight rise in volatile content of samples from layers b and $c$. The condensation of heavy species also improved the quality of the tar product. Once the temperature of the inner-layer particles was high enough, oil shale pyrolysis and secondary reactions of this condensed matter had to occur. Therefore, the central gas collection pipe realized selective cracking of condensed matters, while other non-condensable matter was directly released as final products without significant secondary reactions occurring when passing through the reactor space.

For UV analysis, unsaturated functional groups and heteroatoms in the pyrolysis products must induce light absorption in UV region. This absorbance is proportional to the chromophore concentration, indicating the amount of condensate deposited on the particles. Fig. 4 compares the UV spectra of the condensate on $1 \mathrm{~mL}$ of particles $(0.2-1 \mathrm{~mm})$ taken from layers a-c, and the original oil shale. The absorption peak at around $225 \mathrm{~nm}$, indicating the $\mathrm{C}=\mathrm{C}$ bond of a large alkene, was used as the comparison reference. For each of the reaction temperatures

Table 2 Proximate analysis for oil shale or char taken from different radial positions $(a-c)$

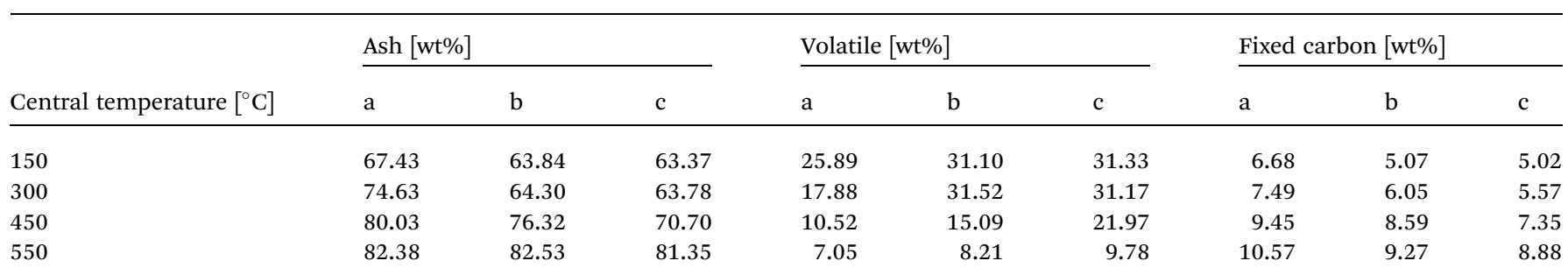



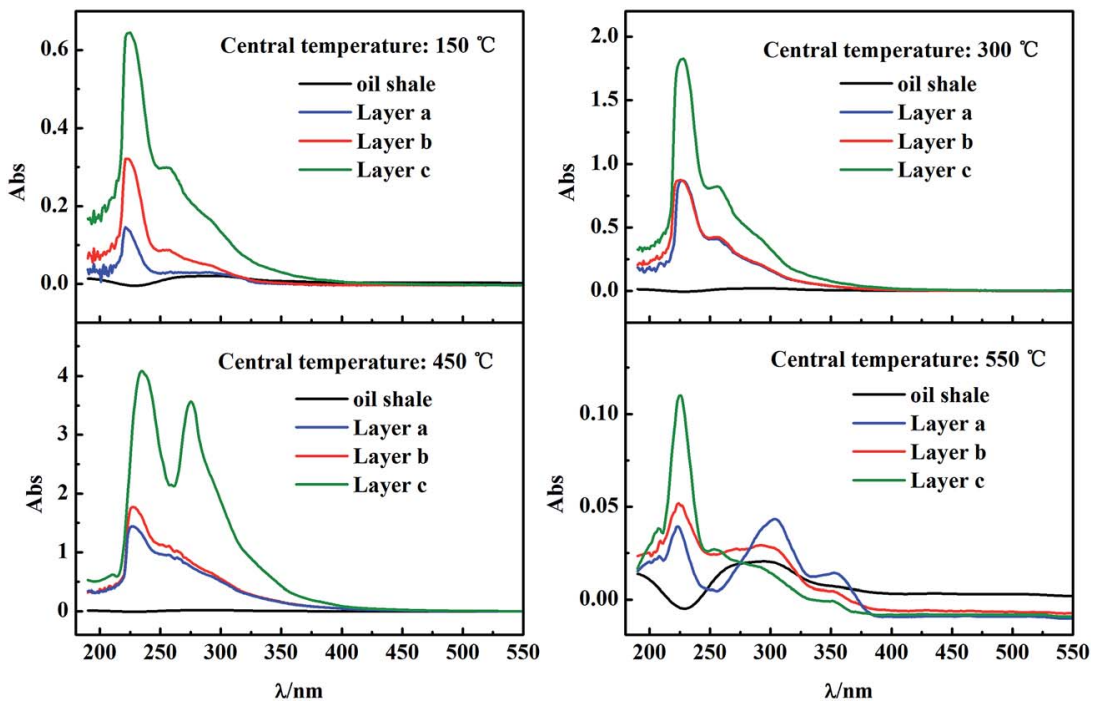

Fig. 4 UV analysis of condensate on particles in different particle layers a-c from pyrolysis terminated at different central temperatures.

compared, the absorbance of observable peaks increased from outer layer a to central layer $\mathrm{c}$, with the original oil shale having the lowest absorbance. This indicated that more chemicals were present on particles in the inner low-temperature layers, further verifying the product flow from the high-temperature outer layer to the bed center and into the central gas collection pipe. UV absorbance for samples from a single layer of the reactor manifested a similar variation with pyrolysis temperature (or time). Absorbance was elevated to a maximum when the plotted central temperature was about $450{ }^{\circ} \mathrm{C}$, and then sharply dropped to a very low value by the end of pyrolysis (scale is different in four sub-plots of Fig. 4). This evidenced the secondary reactions of species condensed on the particle surface. During pyrolysis, noncondensable products directly flow into the central gas collection pipe, but most heavy species with high boiling points must be condensed on the low-temperature surface of particles in the inner layer. As the reaction progresses, the inner bed reached a high temperature, causing re-evaporation and cracking of the condensed components into further pyrolysis products via secondary reactions. Therefore, in the reactor with internals, the heavy species experienced, in succession, generation, condensation, and re-evaporation or cracking, while light species were directly discharged as products. This demonstrated that internals resulted in secondary reactions selectively on only heavy species, affording oil production with high yields (due to no secondary reaction of light species) and quality (only cracking of heavy species).

\subsection{Product generation characteristics}

Previously, we reported pyrolysis product characteristics based on the final yields and qualities of shale oil and pyrolysis gas. ${ }^{12-14}$ This section further characterizes production by analyzing oil and gas products at different reaction times or temperatures at the measured central point. Table 3 shows the product distribution at measured central temperatures of 150, 300,450 and $550{ }^{\circ} \mathrm{C}$. As the reaction progressed, the yields of shale oil and pyrolysis gas increased, while that of char decreased. For the tabulated time, the variation in yield with time was almost linear for all such products. Pyrolysis water production showed little variation during the last stage of reaction because it resulted from water evaporation and decomposition of hydroxy groups at low temperatures. These features of production were different from those in a conventional fixed bed reactor (without internals), which gives obvious peak production at temperatures of $480-530{ }^{\circ} \mathrm{C}^{22-27}$ This difference was caused by oil shale pyrolysis in the reactor with internals occurring layer-by-layer from outside to inside, and the flow and temperature fields in the reactor being controlled to form the desired direction and gradient, respectively.

The shale oil product can be characterized according to boiling points as fractions of gasoline $\left(<180^{\circ} \mathrm{C}\right)$, diesel $(180-350$ $\left.{ }^{\circ} \mathrm{C}\right)$, vacuum gas oil (VGO, $\left.350-500{ }^{\circ} \mathrm{C}\right)$ and heavy oil $\left(>500{ }^{\circ} \mathrm{C}\right)$. Fig. 5 shows the variations in fractions of these distillates with pyrolysis temperature at the measured central point and the yield at each pyrolysis stage at a range of measured central temperatures. In Fig. 5, the fraction was the oil obtained in a test at room temperature to the mentioned individual central temperature, while the yields are for the shale oil product obtained at each temperature range, including $0-150{ }^{\circ} \mathrm{C}, 150-$ $300{ }^{\circ} \mathrm{C}, 300-450{ }^{\circ} \mathrm{C}$ and $450-550{ }^{\circ} \mathrm{C}$. Using the temperature range $150-300^{\circ} \mathrm{C}$ as an example, two pyrolysis experiments were

Table 3 Pyrolysis product distributions using different reaction times in the reactor with internals

\begin{tabular}{lllrlr}
\hline & & \multicolumn{2}{l}{ Yield $[\mathrm{wt} \%]$} & \\
\cline { 3 - 6 } Time $[\mathrm{min}]$ & $\begin{array}{l}\text { Central } \\
\text { temperature }\left[{ }^{\circ} \mathrm{C}\right]\end{array}$ & Char & Oil & Water & Gas \\
\hline 20 & 150 & 97.55 & 0.60 & 0.46 & 1.20 \\
38 & 300 & 91.13 & 2.86 & 2.50 & 3.82 \\
56 & 450 & 80.87 & 7.71 & 4.22 & 8.32 \\
74 & 550 & 75.31 & 11.45 & 4.29 & 11.74
\end{tabular}



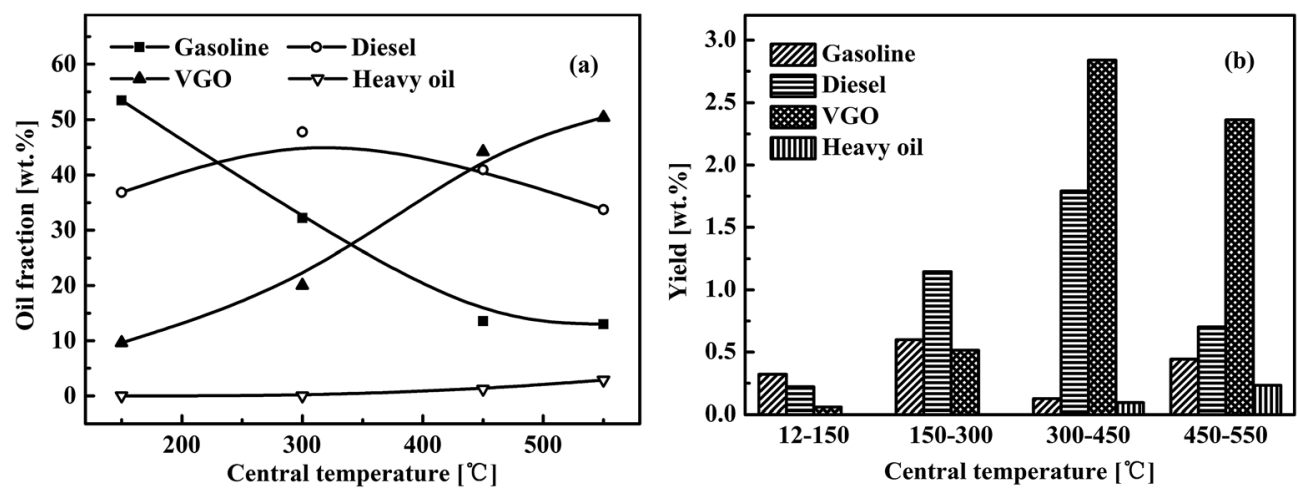

Fig. 5 Variations in (a) oil fraction and (b) yield with changing central temperature in the reactor with internals.

conducted in this range to obtain shale oil yields from room temperature to $150{ }^{\circ} \mathrm{C}$ and $300{ }^{\circ} \mathrm{C}$. Then, by subtraction, the plotted yield was estimated for the temperature range of 150$300{ }^{\circ} \mathrm{C}$, as shown in Fig. $5(\mathrm{~b})$.

Fig. 5(a) clearly shows that no heavy oil was generated by pyrolysis at temperatures below $300{ }^{\circ} \mathrm{C}$ at the measured central point, but the ultimate heavy oil content reached $2.86 \mathrm{wt} \%$ of oil gained at a central temperature of $550{ }^{\circ} \mathrm{C}$. The total VGO yield was $0.57 \mathrm{wt} \%$ up to $300{ }^{\circ} \mathrm{C}$ and $5.20 \mathrm{wt} \%$ at $300-5500^{\circ} \mathrm{C}$. The oils obtained at measured central temperatures of $450^{\circ} \mathrm{C}$ and $550{ }^{\circ} \mathrm{C}$ had VGO contents that reached $44.25 \mathrm{wt} \%$ and $50.43 \mathrm{wt} \%$, respectively. Therefore, heavy components, including VGO and heavy oil, were generated mainly in late stage of pyrolysis at temperatures above $300{ }^{\circ} \mathrm{C}$. The fraction of gasoline in the shale oil product sharply decreased from $53.53 \%$ to about $13.0 \%$ when the measured temperature was raised from $150{ }^{\circ} \mathrm{C}$ to $550{ }^{\circ} \mathrm{C}$. However, the absolute gasoline yield at each reaction stage was low, fluctuating around $0.4 \mathrm{wt} \%$. The heavy products (VGO + heavy oil) decreased the gasoline fraction at high temperatures. Diesel distillate was produced mainly at central temperatures above $300{ }^{\circ} \mathrm{C}$, with the highest yield (1.9 wt\%) obtained at $300-450{ }^{\circ} \mathrm{C}$. The diesel content remained at about $40 \%$ in oils obtained using all tested central temperatures. Diesel production is thought to be caused by the pyrolysis of oil shale and secondary racking of condensate at $400-550{ }^{\circ} \mathrm{C}$. Therefore, the beneficial actions from our mounted internals enabled the production of gasoline and diesel (light oils) in the entire temperature range up to $550^{\circ} \mathrm{C}$, whereas the production of VGO and heavy oil (heavy species) mainly occurred at hightemperature reaction stages $\left(>300{ }^{\circ} \mathrm{C}\right)$. In the reactor with internals, the condensation of heavy matter on inner-layer particles had to occur during earlier reaction stages $\left(<300{ }^{\circ} \mathrm{C}\right.$ at the measured central point). This was a critical process to ensure selective cracking to heavy species.

Fig. 6 shows the GC-MS spectra of oil samples obtained at the tested different central temperatures shown in Fig. 5. The carbon numbers of components were marked to identify alkane peaks. In the first spectrum $\left(150{ }^{\circ} \mathrm{C}\right)$, the relative intensity decreased with increasing carbon number. Raising the central temperature $\left(300,450\right.$, and $\left.550^{\circ} \mathrm{C}\right)$ gradually elevated the relative intensities of carbon numbers above 15. Further pyrolysis and re-evaporation/cracking of heavy species lowered the

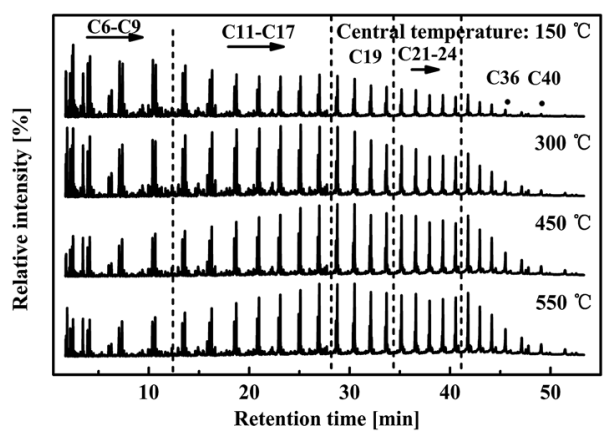

Fig. 6 GC-MS spectra of shale oils from pyrolysis terminated at different central temperatures in the reactor with internals.

relative intensities of groups $\mathrm{C} 6-\mathrm{C} 9$ but increased those of $\mathrm{C} 19$, C21-C24, C36, and C40. This result complied with the preceding distillation analysis, but was the opposite of our general knowledge regarding oil composition variation with pyrolysis temperature in normal fixed bed reactors. ${ }^{19,23}$ Deep cracking of long-chain hydrocarbons in high-temperature wallannulus was expected to cause obvious decomposition of species with carbon numbers above 17 . However, the action of internals caused these high-C species to be released and moderately decomposed in the late stage of pyrolysis.

From GC-MS analysis, the oil components were classified into five types: alkanes, alkenes, aromatics, heteroatom compounds, and cyclohydrocarbons. Their area percentages were calculated by integrating peaks of the GC-MS spectrum. The area percentage was proportional to the content of the indicated chemicals. Fig. 7 shows that the area percentage of aliphatic hydrocarbons (alkane and alkene) was above $80 \%$ in all oils, indicating the aliphatic hydrocarbon base of the shale oil composition. The area percentages for aromatic and heteroatom compounds were both around $10 \%$, while that of cyclohydrocarbon was below $5 \%$. The variation in relative areas with central temperature (pyrolysis stage) revealed that continued pyrolysis at high temperatures reduced the alkenes, aromatics, and cyclohydrocarbons in oil, but gave more alkanes and heteroatom compounds. Considering the chemical structure of these components, the molecular weights of the alkenes, aromatics, and cyclohydrocarbons were much lower than those 


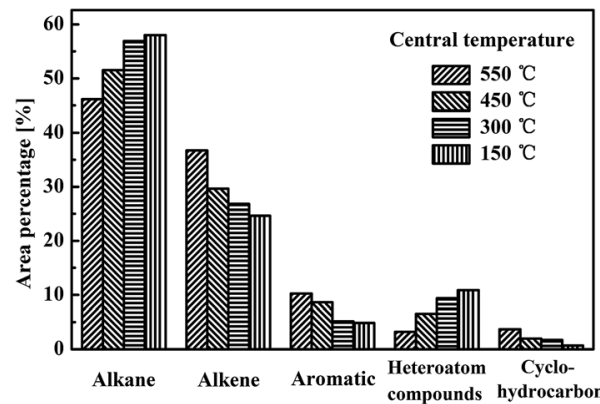

Fig. 7 Major chemical components of shale oils from pyrolysis terminated at different central temperatures in the reactor with internals.

of the alkanes. The carbon numbers of most alkenes, aromatics, and cyclohydrocarbons were below 19, 11, and 16, respectively. Fig. 6 shows the carbon number distribution of the alkanes obtained, indicating that high molecular weight alkane components were present. $\mathrm{C}_{19} \mathrm{H}_{37} \mathrm{~N}, \mathrm{C}_{27} \mathrm{H}_{56} \mathrm{O}$, and $\mathrm{C}_{28} \mathrm{H}_{58} \mathrm{O}$ were detected as the major heteroatomic compounds, with molecular weights higher than the alkenes, aromatics, and cyclohydrocarbons obtained. The boiling point of oil components increases with higher molecular weights. Therefore, alkanes and heteroatomic compounds would condense in the earlier stage of pyrolysis and re-evaporate in the late stage to give a gradually higher percentage, as shown in Fig. 7.

\section{Conclusions}

Pyrolysis of Huadian oil shale in fixed bed reactors with or without internals was conducted to investigate the working mechanism of internals in improving pyrolysis performance. Measuring heating curves of the oil shale particles at the bed center clarified that the particularly designed internals increased heat transfer from the reactor wall to the central layer of oil shale by $30-50 \%$. The internals were further shown to regulate the flow of volatile products in the reactor from the annular high-temperature zone to the central low-temperature region. This caused silica sand loaded in the annular layer of the reactor with internals to maintain its white color, whereas in the reactor without internals the silica sand was blackened, demonstrating a certain degree of coking of the volatiles flowing through the sand particles. Furthermore, because of the regulation of volatile flow by internals, UV analysis of the liquid washing particles demonstrated that the particles taken from the central layer of the reactor with internals contained more deposited surface chemicals, confirming the condensation of heavy components on these particles, which were at relatively low temperatures during the early stages of pyrolysis. The condensed heavy components were re-evaporated or cracked inturn when the central bed temperature was further elevated during late-stage pyrolysis. Consequently, by regulating volatile flow in the reactor from high temperature to low temperature, secondary reactions were selectively restricted to heavy species via a successive process of condensation, evaporation, and cracking. Meanwhile, light components were directly exhausted via the central channel as pyrolysis products. Because the volatiles released from oil shale particles flowed into a lowtemperature region, where only heavy species underwent the aforementioned selective secondary reactions, the shale oil yield continuously increased with increasing heating temperature and maintained a high light content even at higher heating temperatures. Terminating oil shale pyrolysis at central temperatures of $150,300,450$, and $550{ }^{\circ} \mathrm{C}$ further demonstrated that, in the reactor with internals, light species (gasoline + diesel) were produced throughout the entire pyrolysis period, whereas heavy species (VGO + heavy oil) were mainly generated in the late stage. Pyrolysis in the reactor with internals was also shown to produce more alkenes and aromatics in the early reaction stage at low temperatures, but more alkanes in the late stage at higher temperatures.

\section{Acknowledgements}

The study was financed by the National Basic Research Program of China (2014CB744303), National Natural Science Foundation (91534125), and Strategic Priority Research Program of Chinese Academy of Sciences (XDA07010100).

\section{References}

1 J. R. Dyni, Oil Shale, 2003, 20, 193-252.

2 W. Taciuk, Oil Shale, 2013, 30, 1-5.

3 K. Bredow, Oil Shale, 2003, 20, 81-92.

4 J. G. Speight, Shale oil production process, Elsevier, New York, 2012.

5 X. M. Jiang, Z. G. Cui, C. Yan, D. C. Liu, J. R. Qiu and J. B. Li, Fuel, 2002, 81, 793-797.

$6 \mathrm{~J}$. Qian, J. Wang and S. Li, Proceedings of the 18th International Offshore and Polar Engineering Conference, ISOPE, Vancouver, 2008, pp. 19-20.

7 A. R. Brandt, Energy Fuels, 2009, 23, 6253-6258.

8 X. M. Jiang, X. X. Han and Z. G. Cui, Energy, 2007, 32, 772777.

9 I. Öpik, N. Golubev, A. Kaidalov, J. Kann and A. Elenurm, Oil Shale, 2001, 18, 99-108.

10 P. Chaturong and P. Adisak, Powder Technol., 2013, 245, 233240.

11 S. Y. Yang, J. Zhang, Q. C. Yang and Y. Qian, Energy Fuels, 2014, 28, 5557-5564.

12 C. Zhang, R. C. Wu and G. W. Xu, Energy Fuels, 2014, 28, 236244.

13 L. X. Lin, C. Zhang, H. J. Li, D. G. Lai and G. W. Xu, Fuel Process. Technol., 2015, 138, 147-155.

14 L. X. Lin, D. G. Lai, E. W. Guo, C. Zhang and G. W. Xu, Fuel, 2016, 163, 48-55.

15 O. S. Al-Ayed, M. R. Suliman and N. A. Rahman, Appl. Energy, 2010, 87, 2273-2277.

16 O. S. Al-Ayed, M. Matouq, Z. Anbar, A. M. Khaleel and E. AbuNameh, Appl. Energy, 2010, 87, 1269-1272.

17 H. Bar, R. Ikan and Z. Aizenshtat, J. Anal. Appl. Pyrolysis, 1988, 14, 49-71. 
18 G. Yang, Z. H. Wang, Q. M. Xian, F. Shen, C. Sun, Y. Z. Zhang and J. Wu, RSC Adv., 2015, 5, 40117-40125.

19 Y. H. Sun, F. T. Bai, B. C. Liu, Y. M. Liu, M. Y. Guo, W. Guo, Q. W. Wang, X. S. Lü, F. Yang and Y. Yang, Fuel, 2014, 115, 338-346.

20 J. Gersten, V. Fainberg, G. Hetsroni and Y. Shindler, Fuel, 2000, 79, 1679-1686.

21 M. C. Torrente and M. A. GalaÂn, Fuel, 2001, 80, 327-334.

22 V. Dieckmann, H. J. Schenk, B. Horsfield and D. H. Welte, Fuel, 1998, 77, 23-31.

23 L. Ballice, Fuel Process. Technol., 2005, 86, 673-690.

24 H. F. Guo, J. D. Lin, Y. D. Yang and Y. Y. Liu, Fuel, 2014, 118, 186-193.

25 S. Wang, X. M. Jiang, X. X. Han and J. H. Tong, Fuel Process. Technol., 2014, 121, 9-15.

26 P. T. Williams and N. Ahmad, Fuel, 1999, 78, 653-662.
27 F. D. Guffey and T. R. McLendon, Liq. Fuels Technol., 1984, 2, 439-461.

28 T. H. Fletcher, R. Gillis, J. Adams and T. Hall, Energy Fuels, 2014, 28, 2959-2970.

29 J. H. Campbell, G. H. Koskinas, N. D. Stout and T. T. Coburn, In Situ, 1978, 2, 1-47.

30 X. Z. Lan, W. J. Luo, Y. H. Song, J. Zhou and Q. L. Zhang, Energy Fuels, 2015, 29, 7800-7806.

31 D. G. Lai, Z. H. Chen, L. X. Lin, Y. M. Zhang, S. Q. Gao and G. W. Xu, Energy Fuels, 2015, 29, 2219-2226.

32 L. Zhang, B. Zhang, Z. Q. Yang and Y. F. Yan, RSC Adv., 2014, 4, 39145-39155.

33 H. Y. Zhang, J. Zheng, R. Xiao, D. K. Shen, B. S. Jin, G. M. Xiao and R. Chen, RSC Adv., 2013, 3, 5769-5774.

34 H. F. Guo, Q. X. Cheng, Z. Jin, D. Wang, G. W. Xu and Y. Y. Liu, $R S C A d v$. , 2016, 6, 102231-102248. 